\title{
Pemetaan SMA dan SMK Berdasarkan Standar Kompetensi Lulusan, Proses, Pembiayaan Pendidikan, dan Penilaian Pendidikan Menggunakan Analisis Biplot di Kabupaten Minahasa Tenggara
}

\author{
Melky Zadrak Sepang ${ }^{1}$, Djoni Hatidja ${ }^{2}$, Yohanes Langi ${ }^{3}$ \\ ${ }^{1}$ Program Studi Matematika, FMIPA, UNSRAT Manado, melkysepang@gmail.com \\ ${ }^{2}$ Program Studi Matematika, FMIPA, UNSRAT Manado, dhatidja@yahoo.com \\ ${ }^{3}$ Program Studi Matematika, FMIPA, UNSRAT Manado, yarlangi@gmail.com
}

\begin{abstract}
Abstrak
Dinas Pendidikan Kabupaten Minahasa Tenggara belum memiliki data tentang standar nasional pendidikan, maka penelitian mengenai standar nasional pendidikan perlu dilakukan. Tujuan penelitian ini adalah: 1) mendeskripsikan mutu SMA/SMK di Kabupaten Minahasa Tenggara berdasarkan indikator standar nasional pendidikan, yaitu: Standar Kompetensi Lulusan,Standar Proses, Standar Pembiayaan Pendidikan dan Standar Penilaian Pendidikan (Standar Nasional Pendidikan); 2) melakukan pemetaan keunggulan dan kekurangan masing-masing SMA/SMK di Kabupaten Minahasa Tenggara berdasarkan indikator standar Nasional Pendidikan dengan menggunakan analisis Biplot. Analisis Biplot merupakan penyajian grafik dua dimensi yang menampilkan secara simultan objek pengamatan (SMA/SMK) dan peubah (indikator Standar Nasional Pendidikan). Gambaran umum SMA/SMK berdasarkan peubah-peubah standar pendidikan diharapkan dapat memberikan informasi tentang mutu masing-asing SMA/SMK di Kabupaten Minahasa Tenggara. Penelitian ini akan dilaksanakan dengan mengambil data primer di 15 SMA/SMK yang berada di Kabupaten Minahasa Tenggara dan data sekunder di Dinas Pendidikan dan Olahraga Kabupaten Minahasa Tenggara. Peubah-peubah yang diamati adalah Standar Kompetensi Lulusan, Standar Proses, Standar Pengelolaan, Standar Pembiayaan Pendidikan dan Standar Penilaian Pendidikan. Data akan dianlisis dengan menggunakan perangkat Komputer. Hasilnya, menunjukan bahwa SMA/SMK di kabupaten Minahasa Tenggara sudah mempunyai kualitas yang cukup baik SMK 1 Ratahan memiliki siswa terbanyak dari sekolah-sekolah lain dengan jumlah 684 siswa sedangkan SMK Muhamadyah Ratatotok memiliki siswa paling sedikit yaitu 16 siswa dikarenakan sekolah ini baru dibuka dan baru mempunyai siswa kelas X.Hampir Semua sekolah di kabupaten Minahasa Tenggara memiliki biaya pendidikan berasal dari dana bos, bosda dan komite. Kecuali SMK Muhamadyah yang memiliki biaya pendidikan berasal dari muhamadyah.
\end{abstract}

Kata kunci: Analisis Biplot, Standar Nasional Pendidikan

\section{Mapping Senior High School and Vocational School Based On Competency Standards, Process, Financing Education, And Assessment Of Educational Use The Biplot Analysis In Southeast Minahasa Regency}

\begin{abstract}
Southeast Minahasa District Education Office do not yet have data on national education standards, the research on the national standard of education needs to be done. purpose of this study were: 1) to describe the quality of SMA / SMK in Southeast Minahasa Regency based on indicators of national standards of education, namely: Graduates Competency Standards, Standard Process, Financing Education Standards and Assessment Standards of Education (National Standards); 2) mapping the advantages and disadvantages of each SMA / SMK in Southeast Minahasa Regency based on standard indicators of National Education using Biplot analysis. Analysis Biplot is presenting two-dimensional graph that displays simultaneously the object of observation (SMA / SMK) and variable (indicator National Standards). General description SMA / SMK variables based on the standard of education is expected to provide information about the quality of their foreign-SMA / SMK in Southeast Minahasa Regency. This study will be carried out by taking the primary data in 15 SMA / SMK located in Southeast Minahasa Regency and secondary data in the Department of Education and Sports Southeast Minahasa Regency. The observed variables are Competency Standards, Standard Process, Standard Management, Financing Education Standards and Assessment Standards of Education. Data will dianlisis using the computer. As a result, show that SMA / SMK district Southeast Minahasa already have a fairly good quality of SMK 1 Ratahan have students most of the other schools with a number of 684 students while the vocational Muhamadyah Ratatotok have students at least that is 16 students because the school recently opened and new graders have X.Hampir All schools in Southeast Minahasa district to have the cost of education funds from the boss, BOSDA and committees. Unless SMK Muhamadyah who have come from Muhamadyah education costs.
\end{abstract}

Keywords: Biplot Analysis, National Education Standards 


\section{Pendahuluan}

Dalam UUD 1945 alinea keempat yang berisikan cita-cita bangsa Indonesia yakni mencerdaskan kehidupan bangsa karena bangsa yang cerdas adalah bangsa yang kuat. tujuan pendidikan nasional yaitu untuk mengembangkan potensi peserta didik agar menjadi manusia yang beriman dan bertakwa kepada Tuhan Yang Maha Esa, berakhlak mulia, sehat, berilmu, cakap, kreatif, mandiri, dan menjadi warga negara yang demokratis serta bertanggung jawab [1].

Untuk mewujudkan tujuan pendidikan nasional, pemerintah menetapkan 8 Standar Nasional yaitu Standar Kompetensi Lulusan, Standar Isi, Standar Proses, Standar Pendidikan dan Tenaga Kependidikan, Standar Sarana dan Prasarana, Standar Pengelolaan, Standar Pembiayaan Pendidikan dan Standar Penilaian Pendidikan. Dalam Penelitian ini hanya meneliti empat standar nasional pendidikan dari delapan standar yang ada, keempat standar pendidikan nasional itu adalah Standar Kompetensi Lulusan, Standar Proses, Standar Pembiayaan Pendidikan, dan Standar Penilaian Pendidikan.

Analisis biplot adalah salah satu bagian dari analisis peubah ganda (APG) yang dapat menyajikan secara simultan dalam bentuk gambar dua dimensi antara indikator Standar Kompetensi Lulusan, Standar Proses, Standar Pembiayaan Pendidikan, dan Standar Penilaian Pendidikan (sebagai peubah) dengan SMA dan SMK yang ada di Kabupaten Minahasa Tenggara (sebagai objek) [2].

Tujuan penelitian ini yaitu untuk memetakan keunggulan dan kekurangan dari SMA dan SMK di Kabupaten Minahasa Tenggara berdasarkan dengan menggunakan analisis biplot.

\section{Analisis Biplot}

Analisis statistika deskriptif dimensi ganda yang menyajikan secara simultan $n$ objek pengamatan dan $p$ peubah dalam suatu grafik pada suatu bidang dua dimensi, sehingga ciri-ciri dan posisi relatif peubah tersebut dapat dianalisis dinamakan Analisis Biplot [3].

Empat hal penting yang dapat dilihat pada biplot adalah :

1. Hubungan (korelasi) antar peubah, dengan menggunakan biplot peubah akan digambarkan sebagai garis berarah. Dua peubah yang memiliki korelasi positif tinggi akan digambarkan sebagai dua buah garis dengan arah yang sama, atau membentuk sudut yang sempit. Apabila dua peubah yang memiliki korelasi negatif tinggi akan digambarkan dalam bentuk dua garis yang arahnya berlawanan, atau membentuk sudut yang lebar (tumpul). Sedangkan dua buah peubah yang tidak berkorelasi akan digambarkan dalam bentuk dua garis yang mendekati $90^{\circ}$ (siku-siku).

2. Keragaman peubah, informasi ini digunakan untuk melihat apakah ada peubah tertentu yang nilainya hampir sama setiap objek ada yang sama besar dan ada juga yang sangat kecil. Dengan informasi ini, bisa diperkirakan pada peubah mana strategi tertentu harus ditingkatkan, serta sebaliknya.Dalam biplot, peubah dengan keragaman kecil digambarkan dengan vektor yang pendek, sedangkan peubah yang ragamnya besar digambarkan sebagai vektor yang panjang.

3. Kedekatan antar objek, informasi ini bisa dijadikan panduan objek mana yang memiliki kemiripan karakteristik dengan objek tertentu. Dalam biplot, dua objek dengan karakteristik sama akan digambarkan sebagai dua titik yang posisinya berdekatan.

4. Nilai peubah pada suatu objek, informasi ini digunakan untuk melihat keunggulan dari setiap objek. Objek yang terletak searah dengan arah dari suatu peubah dikatakan bahwa pada objek tersebut nilainya diatas rata-rata. Sebaliknya jika objek lain terletak berlawanan dengan arah dari peubah tersebut maka objek tersebut memiliki nilai dekat dengan rata-rata [4].

Analisis biplot didasarkan pada penguraian nilai-nilai singular suatu matriks. Penguraian nilai singular dari suatu matriks merupakan teorema dasar yang banyak digunakan dalam perhitungan matriks. Definisi dari SVD adalah suatu matriks $X$ yang merupakan matriks data dengan $n$ objek dan $p$ peubah diuraikan menjadi:

$$
X=U L A^{\prime}
$$

Matriks $U$ dan $A$ adalah matriks berukuran $(n x r)$ dan $(p x r)$ sedemikian sehingga

$U^{\prime} U=A^{\prime} A=I_{r}$ (matriks identitas berdimensi r). $L$ adalah matriks diagonal berukuran

$\left(\begin{array}{lll}r & x & r\end{array}\right)$ yang unsur-unsur diagonalnya merupakan akar pangkat dua dari akar ciri $X^{\prime} X$ sehingga $\sqrt{\lambda_{1}} \geq \sqrt{\lambda_{2}} \geq \ldots \geq \sqrt{\lambda_{r}}$. dengan $\lambda_{\mathrm{i}}$ adalah akar ciri dari matriks $X^{\prime} X$. Unsur-unsur diagonal dari matriks $L$ disebut nilai singular matriks $X$ dan kolom- kolom matriks $A$ adalah vektor ciri dari $X^{\prime} X$ yang berpadanan dengan $\lambda$. Dengan penjabaran persamaan (1) menjadi:

$$
X=U L^{\alpha} L^{1-\alpha} A^{\prime}
$$

untuk $0 \leq \alpha \leq 1$, 
jika definisikan $G=U L^{\alpha}$ dan $H^{\prime}=L^{1-\alpha} A^{\prime}$, persamaan (2) dapat ditulis: $X=G H^{\prime}$

Keakuratan dari biplot dalam menerangkan tingkat keragaman dari matriks data asal dirumuskan sebagai berikut:

$$
\rho=\frac{\left(\lambda_{1}+\lambda_{2}\right)}{\sum_{k=1}^{p} \lambda_{K}}
$$

dimana : $\lambda_{1}=$ akar ciri terbesar pertama; $\lambda_{2}=$ akar ciri terbesar kedua; $\lambda_{\mathrm{k}}=$ akar ciri terbesar ke-k; $\rho=$ tingkat keakuratan. Jika $\rho$ semakin mendekati nilai satu maka biplot penyajiannya semakin baik dalam memberikan informasi [5].

\section{Metodologi Penelitian}

Data yang digunakan dalam penelitian ini berasal dari data primer tahun 2015. Data primer diambil pada seluruh SMA dan SMK di Kabupaten Minahasa Tenggara (15 SMA/SMK). Data sekunder juga diambil di Dinas Pendidikan Pemuda dan Olahraga Kabupaten Minahasa Tenggara pada bulan Januari-Februari 2015.

\subsection{Waktu dan Tempat Penelitian}

Data yang akan digunakan dalam penelitian ini berasal dari data primer (berupa Kuesioner) tahun 2015. Data primer diambil pada seluruh SMA dan SMK di Kabupaten Minahasa Tenggara (15 SMA/SMK). Data primer yang diambil merupakan data populasi SMA/SMK di Kabupaten Minahasa Tenggara. Data sekunder juga diambil di Dinas Pendidikan dan Olahraga Kabupaten Minahasa Tenggara pada bulan Januari-Februari 2015.

\subsection{Objek Penelitian}

Objek dari penelitian ini adalah $15 \mathrm{SMA} / \mathrm{SMK}$ yaitu:

1. SMA Advent Ratahan

2. SMAN 1 Ratahan

3. SMAN 2 Ratahan

4. SMK N 1 Ratahan

5. SMAN 1 Touluaan

6. SMK N 1 Touluaan

7. SMA Kristen Ratatotok

8. SMA Muhamadyah Ratatotok
9. SMAN 1 Belang

10. SMAN 1 Posumaen

11. SMAN 1 Tombatu

12. SMK Nasional Molompar

13. SMK Muhamadya Ratatotok

14. SMK N 1 Posumaen

15. SMK Kristen Tombatu

\subsection{Peubah Penelitian}

Peubah yang diamati yaitu seperti disajikan pada tabel $1-4$.

Tabel 1. Peubah Standar Kompetensi Lulusan (X1)

\begin{tabular}{|c|l|}
\hline Kode & Nama Peubah \\
\hline X1A & Standar Kompetensi Lulusan: \\
\hline X11 & Nilai rata-rata mata pelajaran agama siswa kelas XII \\
\hline X12 & Nilai rata-rata mata pelajaran Pendidikan Kewarganegaraan kelas XII \\
\hline X13 & Nilai rata-rata mata pelajaran Bahasa Indonesia kelas XII \\
\hline X14 & Nilai rata-rata mata pelajaran Bahasa Ingris kelas XII \\
\hline X15 & Nilai rata-rata mata pelajaran Matematika kelas XII \\
\hline X16 & Nilai rata-rata mata pelajaran Sejarah kelas XII \\
\hline X17 & Nilai rata-rata mata pelajaran Fisika kelas XII \\
\hline X18 & Nilai rata-rata mata pelajaran Kimia kelas XII \\
\hline X19 & Nilai rata-rata mata pelajaran Biologi kelas XII \\
\hline X110 & Nilai rata-rata mata pelajaran Ekonomi kelas XII \\
\hline X111 & Nilai rata-rata mata pelajaran Geografi kelas XII \\
\hline X112 & Nilai rata-rata mata pelajaran sosiologi kelas XII \\
\hline X113 & Nilai rata-rata mata pelajaran Seni dan Budaya kelas XII \\
\hline
\end{tabular}




\begin{tabular}{|l|l|}
\hline X114 & Nilai rata-rata mata pelajaran Ketrampilan kelas XII \\
\hline X115 & Nilai rata-rata mata pelajaran pendidikan jasmani dan olahraga XII \\
\hline X116 & Nilai rata-rata mata pelajaran Teknologi Informasi dan Komputer kelas XII \\
\hline X1B & Standar Kompetensi Lulusan : \\
\hline X117 & Nilai rata-rata Ujian Nasional (UAN) lulusan 2014 \\
\hline X118 & Nilai rata-rata UN siswa yang diterima 2011 \\
\hline X119 & Nilai rata-rata siswa kelas X \\
\hline X120 & Nilai Rata-rata siswa kelas XI \\
\hline X121 & Nilai Rata-rata siswa kelas XII \\
\hline
\end{tabular}

Tabel 2. Peubah Standar Proses (X2)

\begin{tabular}{|c|l|}
\hline Kode & \\
\hline X2 & Standar Proses: \\
\hline X21 & Silabus \\
\hline X22 & Rencana pelaksanaan pembelajaran \\
\hline X23 & Standar kompetensi dan kompetensi dasar \\
\hline X24 & Materi ajar \\
\hline X25 & Jumlah siswa kelas X \\
\hline X26 & Jumlah siswa kelas XI \\
\hline X27 & Jumlah siswa Kelas XII \\
\hline X28 & Jumlah ruang dengan siswa $\leq 32$ \\
\hline X29 & Jumlah ruang dengan siswa $>32$ \\
\hline X210 & - Penilaian \\
\hline X211 & - Pengawasan proses pembelajaran \\
\hline
\end{tabular}

Tabel 3. Peubah Standar Pembiayaan Pendidikan (X3)

\begin{tabular}{|c|l|}
\hline Kode & \multicolumn{1}{|c|}{ Nama Peubah } \\
\hline X3 & Standar Pembiayaan Pendidikan: \\
\hline X31 & Biaya untuk bahan atau peralatan pendidikan habis pakai \\
\hline X32 & $\begin{array}{l}\text { Biaya operasi pendidikan tak langsung (air, telepon pemeliharaan } \\
\text { sarana dan prasarana, uang lembur, transportasi }\end{array}$ \\
\hline
\end{tabular}

Tabel 4. Peubah Standar Penilaian Pendidikan (X4)

\begin{tabular}{|c|l|}
\hline Kode & \multicolumn{1}{|c|}{ Nama Peubah } \\
\hline X41 & Standar Penilaian Pendidikan \\
\hline
\end{tabular}

\subsection{Metode Analisis}

Metode analisis yang dilakukan dengan analisis biplot dengan langkah- langkah sebagai berikut :

1. Pemasukan data (matriks data X) (dengan perangkat lunak Statistika untuk menstandarisasi matriks data X).

2. Standarisasi matriks $X$ (dengan perangkat lunak Statistika untuk menstandarisasi matriks dara $X$ ).

3. Penguraian matriks $X$ yang telah distandarisasi dengan SVD.

4. Penghitungan matriks $\mathrm{H}=\mathrm{AL}$ dan $\mathrm{G}=\mathrm{UL}$.

5. Plot matriks $\mathrm{G}$ dan $\mathrm{H}$ secara tumpang tindih.

Langkah 3,4,dan 5 dilakukan dengan menggunakan perangkat lunak komputer yaitu Analisis Biplot.

\section{Hasil dan Pembahasan}

\subsection{Analisis Biplot}

Dalam Analisis Biplot ini hanya menggunakan empat standar nasional pendidikan yaitu Standar Kompetensi Lulusan A, Standar Kompetensi Lulusan B, Standar Proses dan Standar Penilaian 
Pendidikan. Sementara untuk Standar Pembiayaan Pendidikan tidak digunakan dalam analisis Biplot karena nilainya sama untuk semua objek penelitian jadi Standar tersebut mempunyai keragaman nol (0).

Setelah menjalankan program makro biplot dan input data melalui perangkat lunak Komputer, maka diperoleh hasil yaitu :

\subsubsection{Analisi Biplot SMA}

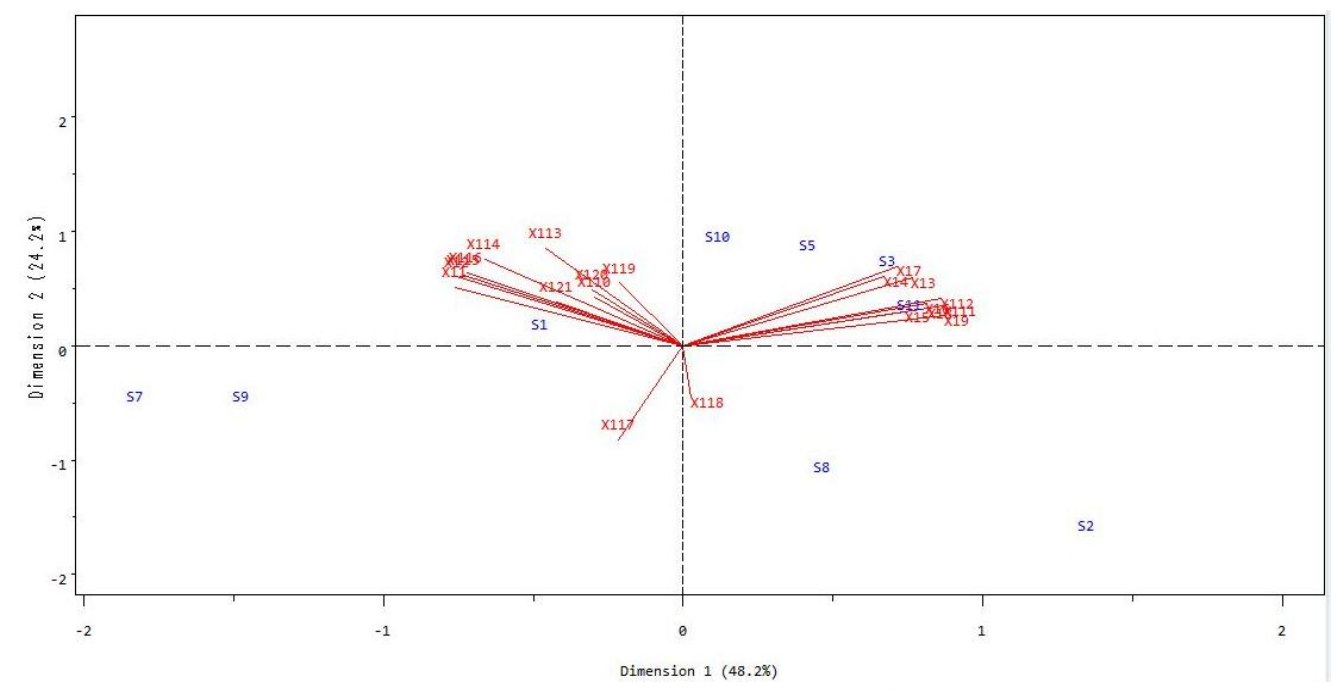

Gambar 1. Plot peubah Standar Kompetensi Lulusan SMA

Dari Gambar 1 dapat dilihat bahwa, SMAN 1 Posumaen (S10), SMAN 2 Ratahan (S3), SMAN 1 Touluaan (S5), SMAN 1 Tombatu (S11) memiliki karakteristik yang hampir sama untuk standar kompetensi lulusan karena posisi keempat sekolah tersebut saling berdekatan.

Keragaman peubah dapat dilihat pada gambar, untuk objek atau peubah yang memiliki vektor yang panjang berarti memiliki keragaman yang besar untuk sebaliknya vektor yang pendek memiliki keragaman yang kecil. Keragaman yang diterangkan oleh dimensi 1 sebesar $48.2 \%$ dan dimensi 2 sebesar $24.2 \%$ sehingga total keragaman sebesar $72.3 \%$. Rasio skala yang digunakan dalam biplot adalah 1 . Untuk gambar diatas menunjukan bahwa variabel Nilai rata-rata mata pelajaran Keterampilan kelas XII memiliki vektor terpanjang, jadi Nilai Keterampilan memiliki ragam yang besar. Untuk nilai rata-rata UN siswa yang diterima memiliki vektor terpendek jadi nilai rata-rata UN siswa yang diterima memiliki ragam yang kecil.

Peubah-peubah yang mempunyai korelasi positif tinggi adalah X13, X14, X16, X17, X18, X19, X111, X112 karena peubah-peubah tersebut membentuk garis berarah dengan arah yang sama dan membetuk sudut lancip. Selain itu ada juga peubah-peubah yang memiliki garis berarah dengan arah yang sama yaitu, X11, X12, X15, X110, X113, X114, X115, X116, X119, X120, X121 hal ini berarti peubahpeubah tersebut mempunyai korelasi positif tinggi, maka untuk kedua kelompok peubah tersebut memiliki korelasi negatif tinggi.

Sekolah SMAN 2 Ratahan (S3) memiliki keunggulan pada peubah X31, X14, X17 karena peubah tersebut memiliki jarak terdekat antara objek dengan peubah, untuk SMAN 1 Tombatu (S11) memiliki keunggulan pada peubah X15, X16, X19, X112, X111 karena peubah tersebut memiliki jarak terdekat antara objek dengan peubah.

Dari Gambar 2 dapat dilihat bahwa, SMAN 1 Posumaen (S10) dan SMA Kristen Ratatotok (S7) serta SMA 1 Ratahan (S2) dan SMAN 1 Touluaan (S5) memiliki karakteristik yang hampir sama untuk standar proses karena posisi kedua sekolah tersebut saling berdekatan.

Keragaman peubah dapat dilihat pada gambar, untuk objek atau peubah yang memiliki vektor yang panjang berarti memiliki keragaman yang besar untuk sebaliknya vektor yang pendek memiliki keragaman yang kecil. Keragaman yang diterangkan oleh dimensi 1 sebesar $72.3 \%$ dan dimensi 2 sebesar $20.3 \%$ sehingga total keragaman sebesar $93.2 \%$. Rasio skala yang digunakan dalam biplot adalah 1 . Untuk gambar diatas menunjukan bahwa variabel Jumlah siswa kelas XI sangat beragam karena memiliki vektor terpanjang sedangkan untuk variabel Jumlah ruang dengan siswa $\leq 32$ memiliki keragaman yang kecil karena memiliki vektor terpendek. 


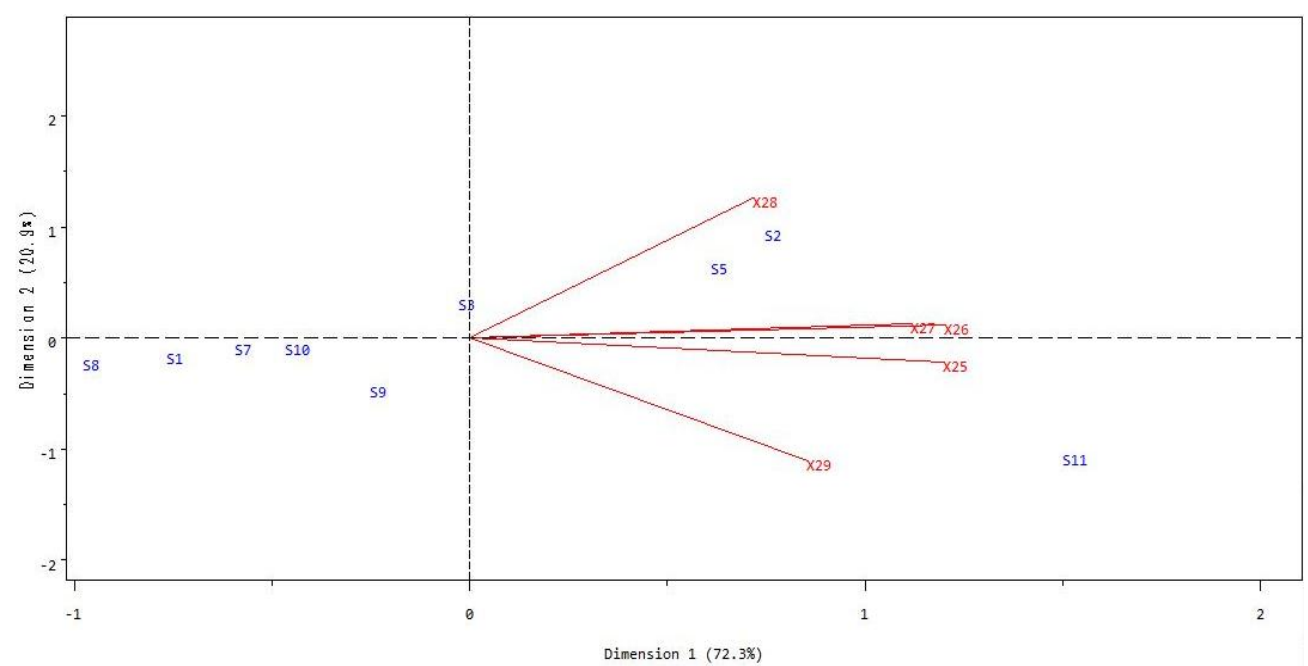

Gambar 2. Plot Peubah Standar Proses SMA

Peubah-peubah dalam standar proses membentuk garis berarah dan membentuk sudut lancip, hal ini menunjukan bahwa peubah-peubah pada standar proses ini memiliki korelasi positif tinggi.

SMAN 1 Ratahan (S2) dan SMAN 1 Touluaan (S5) memiliki keunggulan pada variabel Jumlah ruang siswa $\leq 32$ sedangkan untuk SMAN 1 Tombatu (S11) memiliki keunggulan pada variabel Jumlah siswa kelas X, jumlah siswa kelas XI, jumlash siswa kelas XII, dan jumlah ruang dengan siswa > 32 karena variabel tersebut searah dan dekat dengan objek pengamatan.

\subsubsection{Analisis Biplot SMK}

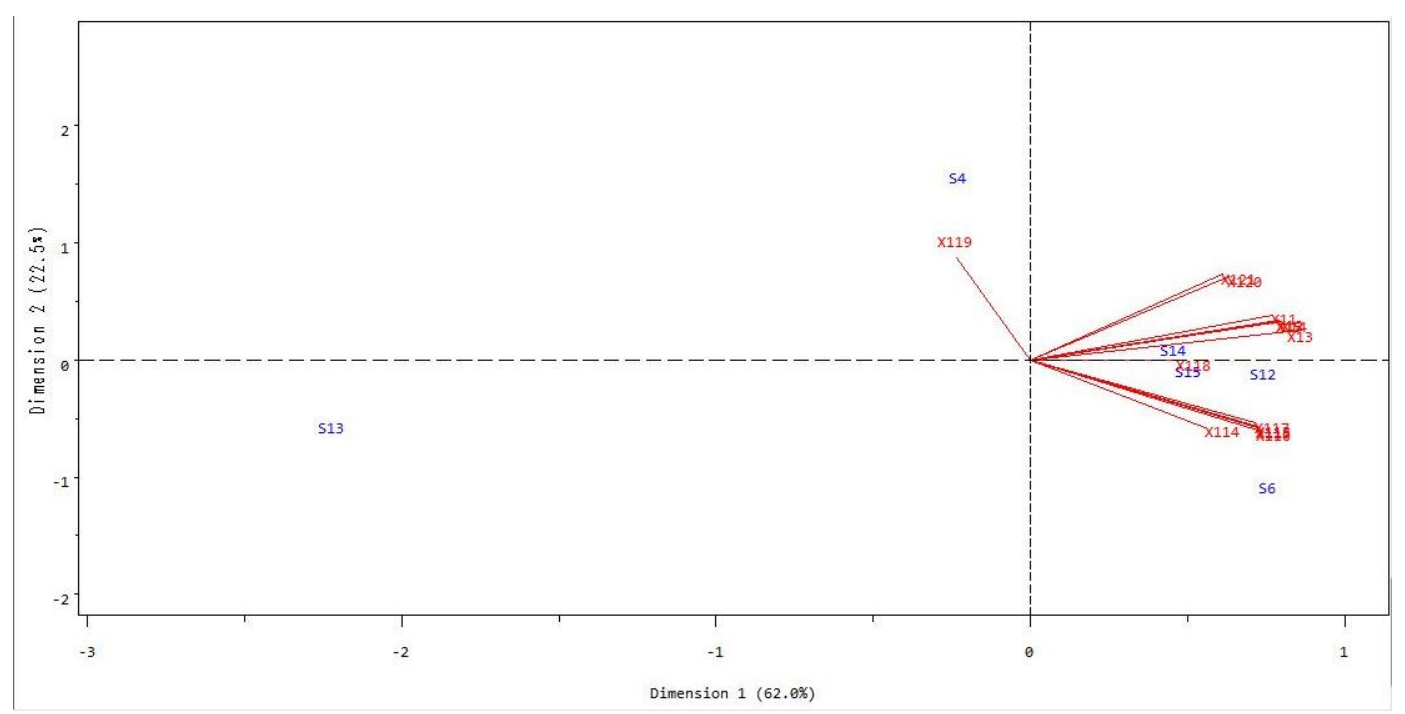

Gambar 3. Plot Peubah Standar Kompetensi Lulusan SMK

Pada Gambar 3 dapat dilihat bahwa, SMK Nasional Molompar (S12), SMK N 1 Posumaen (S14), dan SMK Kristen Tombatu memiliki karakteristik yang hampir sama untuk standar kompetensi lulusan karena posisi keempat sekolah tersebut saling berdekatan.

Keragaman peubah dapat dilihat pada gambar, untuk objek atau peubah yang memiliki vektor yang panjang berarti memiliki keragaman yang besar untuk sebaliknya vektor yang pendek memiliki keragaman yang kecil. Keragaman yang diterangkan oleh dimensi 1 sebesar 62.0\% dan dimensi 2 sebesar $22.5 \%$ sehingga total keragaman sebesar $84.5 \%$. Rasio skala yang digunakan dalam biplot adalah 1 . Untuk gambar diatas menunjukan bahwa variabel Nilai rata-rata kelas XI memiliki vektor terpanjang, jadi Nilai rata-rata kelas $\mathrm{X}$ memiliki ragam yang besar. Untuk nilai rata-rata UN siswa yang diterima memiliki vektor terpendek jadi nilai rata-rata UN siswa yang diterima memiliki ragam yang kecil.

Peubah-peubah yang mempunyai korelasi positif tinggi adalah X121 dan X126 karena peubahpeubah tersebut membentuk garis berarah dengan arah yang sama dan membetuk sudut lancip. Selain itu ada juga peubah-peubah yang memiliki garis berarah dengan arah yang sama yaitu, X114, X115, X116, 
X117 serta X11, X12, X13, X14, X15 hal ini berarti peubah-peubah tersebut mempunyai korelasi positif tinggi, serta untuk ketiga kelompok peubah ini masih memiliki korelasi pisitif tinggi.

SMKN Posumaen (S14) dan SMK Kristen Molompar (S15) memiliki keunggulan pada peubah nilai rata-rata UN siswa yang diterima karena posisi peubah Nilai rata-rata UN siswa yang diterima berdekatan dengan objek pengamatan SMKN Posumaen (S14) dan SMK Kristen Molompar (S15).

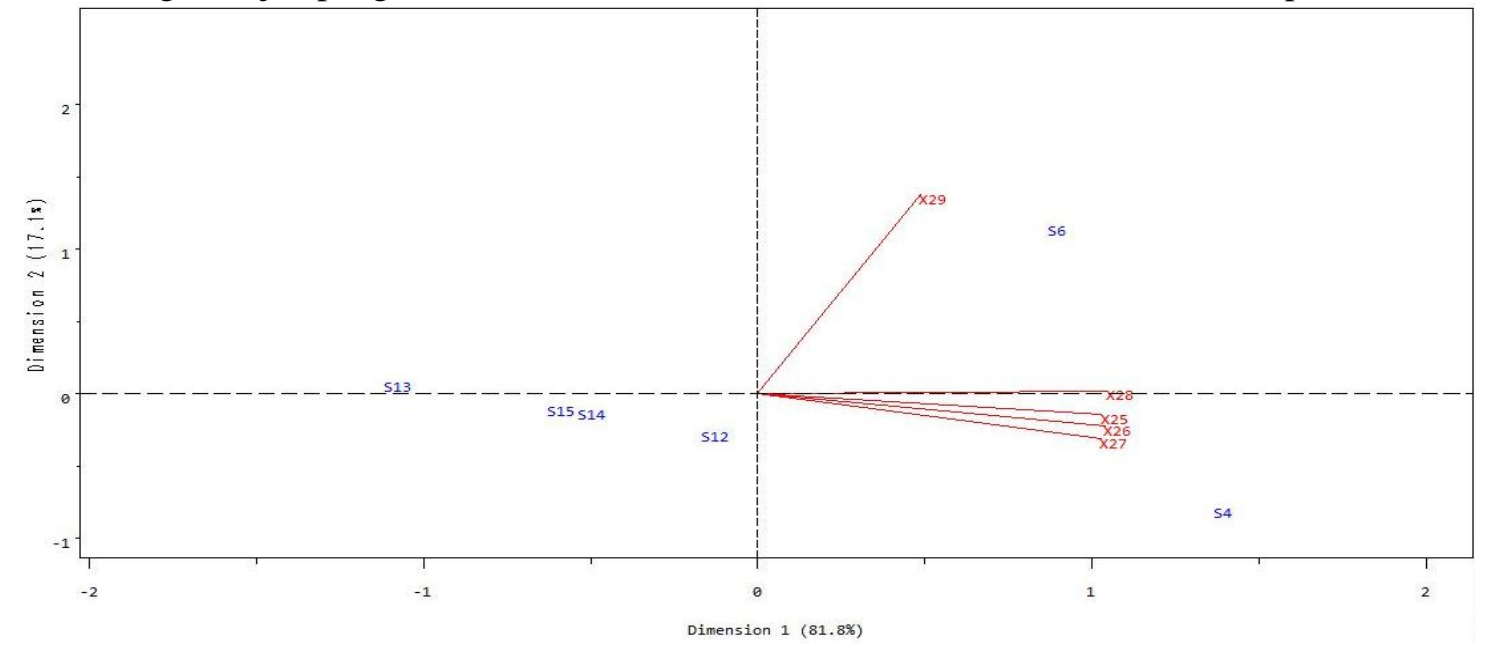

Gambar 4. Plot peubah Standar Proses SMK

Dari gambar 4 dapat dilihat bahwa, SMK Nasional Molompar (S12), SMK N 1 Posumaen (S14), dan SMK Kristen Tombatu memiliki karakteristik yang hampir sama untuk standar proses karena posisi keempat sekolah tersebut saling berdekatan

Keragaman peubah dapat dilihat pada gambar, untuk objek atau peubah yang memiliki vektor yang panjang berarti memiliki keragaman yang besar untuk sebaliknya vektor yang pendek memiliki keragaman yang kecil. Keragaman yang diterangkan oleh dimensi 1 sebesar $81.8 \%$ dan dimensi 2 sebesar $17.1 \%$ sehingga total keragaman sebesar 93.2\%. Rasio skala yang digunakan dalam biplot adalah 1 . Untuk gambar diatas menunjukan bahwa variabel jumlah ruang dengan siswa $>32$ sangat beragam karena memiliki vektor terpanjang sedangkan untuk variabel jumlah siswa kelas $\mathrm{X}$ memiliki keragaman yang kecil karena memiliki vektor terpendek.

Peubah-peubah dalam standar proses membentuk garis berarah dan membentuk sudut lancip, hal ini menunjukan bahwa peubah-peubah pada standar proses ini memiliki korelasi positif tinggi.

SMK 1 Ratahan (S4) memiliki keunggulan pada hampir variabel yaitu jumlah siswa kelas X, jumlah siswa kelas XI, jumlah siswa kelas XII, dan jumlah ruang dengan siswa $\leq 32$, sedangkan untuk SMK N 1 Touluaan (S6) memiliki keunggulan pada peubah jumlah ruang ruang dengan siswa > 32 .

\subsubsection{Plot gabungan Standar Kompetensi Lulusan A dan B,Standar Proses, Standar Penilaian Pendidikan (X1A, XB, X2, X4).}

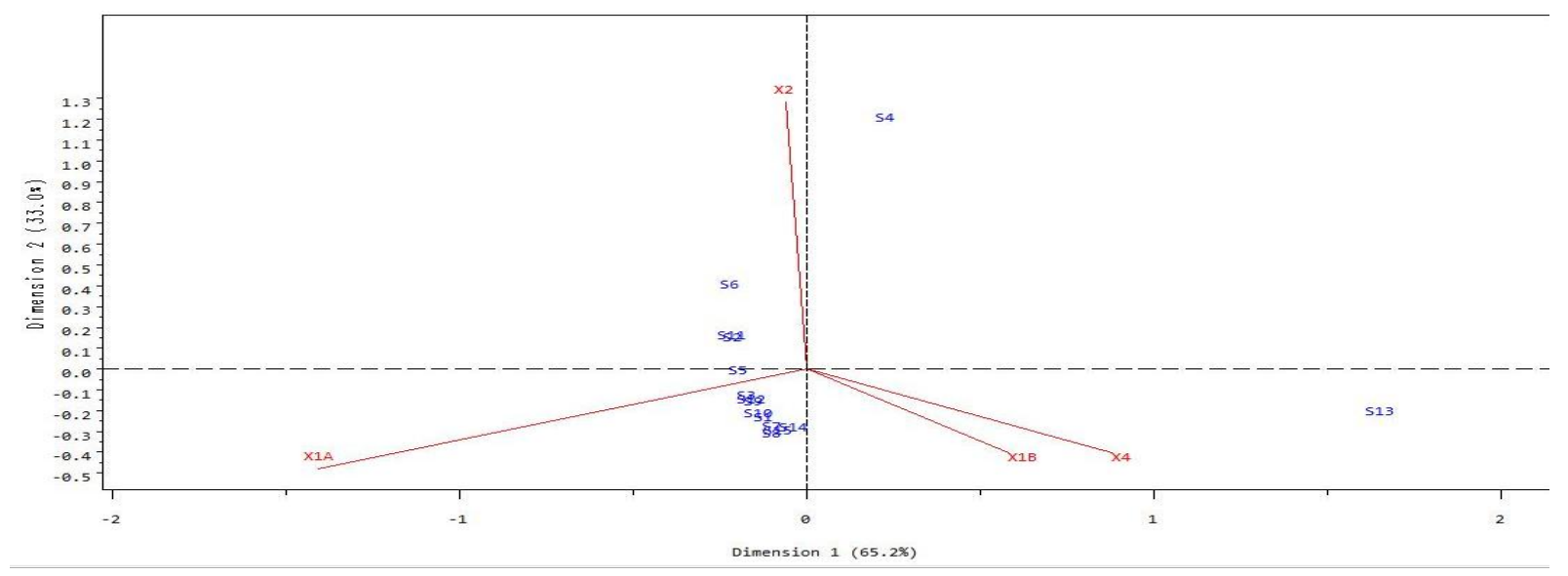

Gambar 5. Plot gabungan Standar Kompetensi Lulusan A dan B,Standar Proses, Standar PenilaianPendidikan (X1A, XB, X2, X4). 
Dari gambar 5 dapat dilihat bahwa, SMA Advent Ratahan (S1) SMAN 1 Belang (S9), SMAN 1 Ratahan (S2), SMAN 1 Posumaen (S10), SMAN 2 Ratahan (S3), SMAN 1 Tombatu (S11), SMK Nasional Molompar (12), SMAN 1 Touluaan (S5), SMK N 1 Touluaan (S6), SMK N 1 Posumaen (S14), SMA Kristen Ratatotok (S7), SMK Kristen Tombatu (S15), SMA Muhamadyah Ratatotok (S8), memiliki karakteristik yang hampir sama karena posisi sekolah-sekolah tersebut saling berdekatan

Keragaman peubah dapat dilihat pada gambar, untuk objek atau peubah yang memiliki vektor yang panjang berarti memiliki keragaman yang besar untuk sebaliknya vektor yang pendek memiliki keragaman yang kecil. Keragaman yang diterangkan oleh dimensi 1 sebesar $65.2 \%$ dan dimensi 2 sebesar $33.0 \%$ sehingga total keragaman sebesar 98.8\%. Rasio skala yang digunakan dalam biplot adalah 1 . Untuk gambar diatas menunjukan bahwa peubah Standar Kompetensi Lulusan A (X1A) dimana dalam peubah ini adalah semua gabungan nilai rata-rata mata pelajaran kelas XII sangat beragam karena memiliki vektor terpanjang sedangkan untuk peubah Standar Kompetensi Lulusan B (X1B) yang temasuk pada gabungan peubah ini adalan nilai rata-rata kelas X,XI,XII dan nilai UN Lulusan serta UN diterima memiliki keragaman yang kecil karena memiliki vektor terpendek.

Peubah-peubah dalam gabungan peubah ini yang mempunyai korelasi positif tinggi adalah Standar Kompetensi Lulusan B (X1B) dan Standar Penilaian Pendidikan (X4) untuk peubah-peubah lain mempunyai korelasi negatif tinggi.

SMKN 1 Ratahan (S4) memiliki keunggulan pada Peubah Standar Proses (X2). SMA Advent Ratahan (S1) SMAN 1 Belang (S9), SMAN 1 Ratahan (S2), SMAN 1 Posumaen (S10), SMAN 2 Ratahan (S3), SMAN 1 Tombatu (S11), SMK Nasional Molompar (12), SMAN 1 Touluaan (S5), SMK N 1 Touluaan (S6), SMK N 1 Posumaen (S14), SMA Kristen Ratatotok (S7), SMK Kristen Tombatu (S15), SMA Muhamadyah Ratatotok (S8) memiliki keunggulan pada Peubah Standar Kompetensi Lulusan A (X1A). Untuk SMK Muhamadya Ratatotok (S13) bukan golongkan sekolah yang nilainya dibawah ratarata tapi karena sekolah ini baru didirikan dan baru memiliki siswa kelas X.

\section{Kesimpulan}

Berdasarkan Plot gabungan 3 Standar nasional didapat hasil menunjukan bahwa SMKN 1 Ratahan (S4) memiliki keunggulan pada Peubah Standar Proses (X2). SMA Advent Ratahan (S1) SMAN 1 Belang (S9), SMAN 1 Ratahan (S2), SMAN 1 Posumaen (S10), SMAN 2 Ratahan (S3), SMAN 1 Tombatu (S11), SMK Nasional Molompar (12), SMAN 1 Touluaan (S5), SMK N 1 Touluaan (S6), SMK N 1 Posumaen (S14), SMA Kristen Ratatotok (S7), SMK Kristen Tombatu (S15), SMA Muhamadyah Ratatotok (S8) memiliki keunggulan pada Peubah Standar Kompetensi Lulusan A (X1A). Untuk SMK Muhamadya Ratatotok (S13) bukan golongkan sekolah yang nilainya dibawah rata-rata tapi karena sekolah ini baru didirikan dan baru memiliki siswa kelas X.

\section{Daftar Pustaka}

[1] Undang-Undang Republik Indonesia Nomor 20 Tahun 2003 Tentang Sistem Pendidikan Nasional.

[2] Daman. R., D.Hatidja. 2012. Pemetaan SMP- SMP di Kabupaten Minahasa Tenggara, Sulawesi Utara berdasarkan Standar Pendidikan dan Tenaga Kependidikan, Standar Sarana dan Prasarana, Standar Pengelolaan dan Standar Pembiayaan Pendidikan dengan Menggunakan Analisis Biplot. De Cartesian. 1(1): 27 - 33.

[3] Joliffe, I.T. 1986. Principal Component Analysis.Springer. Verlag. New York.

[4] Mattjik,A.A. M.Sumertajaya, Wijayanto, Indahwati.A, Kurnia.B, Sartono. 2004. Modul Teori Pelatihan Analisis Multivariat. Departemen Statistika FMIPA IPB, Bogor.

[5] Everit, B. 1978. Graphical Techniques for Multivariate Data. Heinermann Educational Books. 